\title{
Pseudoxanthomonas koreensis sp. nov. and Pseudoxanthomonas daejeonensis sp. nov.
}

\author{
Deok-Chun Yang, ${ }^{1}$ Wan-Taek $\mathrm{Im}^{2}$ Myung Kyum Kim${ }^{2}$ \\ and Sung-Taik Lee ${ }^{2}$ \\ ${ }^{1}$ Department of Oriental Medicinal Material and Processing, College of Life Science, Kyung \\ Hee University, 1 Seocheon, Kihung Yongin, Kyunggi 449-701, South Korea \\ ${ }^{2}$ Environmental and Molecular Microbiology Laboratory, Department of Biological Sciences, \\ KAIST (Korea Advanced Institute of Science and Technology), 373-1 Guseong-dong, \\ Yuseong-gu, Daejeon 305-701, South Korea
}

Correspondence

Sung-Taik Lee

e_stlee@kaist.ac.kr

\begin{abstract}
Gram-negative, non-spore-forming, rod-shaped bacteria, $\mathrm{T} 7-09^{\top}$ and $\mathrm{TR}^{-}-08^{\top}$, were isolated from soil from a ginseng field in South Korea and characterized to determine their taxonomic position. 16S rRNA gene sequence analysis showed that the two isolates shared $99.5 \%$ sequence similarity. Strains $\mathrm{T} 7-09^{\top}$ and $\mathrm{TR} 6-08^{\top}$ were shown to belong to the Proteobacteria and showed the highest levels of sequence similarity to Pseudoxanthomonas broegbernensis DSM $12573^{\top}$ (98.1\%), Pseudoxanthomonas mexicana AMX 26B ${ }^{\top}$ (97·4-97.5\%), Pseudoxanthomonas japonensis 12-3' (96.5-96.6\%), Pseudoxanthomonas taiwanensis ATCC BAA $-404^{\top}(95 \cdot 7 \%)$ and Xanthomonas campestris ATCC $33913^{\top}(96 \cdot 3-96 \cdot 5 \%)$. The sequence similarity values with respect to any species with validly published names in related genera were less than $96.5 \%$. The detection of a quinone system with Q-8 as the predominant compound and a fatty acid profile with $\mathrm{C}_{15: 0}$ iso as the predominant acid supported the assignment of the novel isolates to the order 'Xanthomonadales'. The two isolates could be distinguished from the established species of the genus Pseudoxanthomonas by the presence of quantitative unsaturated fatty acid $\mathrm{C}_{17: 1}$ iso $\omega 9 \mathrm{c}$ and by their unique biochemical profiles. The results of DNA-DNA hybridization clearly demonstrated that T7-09 ${ }^{\top}$ and TR6-08 ${ }^{\top}$ represent separate species. On the basis of these data, it is proposed that T7-09 ${ }^{\top}(=\mathrm{KCTC}$ $12208^{\top}=$ IAM $\left.15116^{\top}\right)$ and TR6-08 ${ }^{\top}\left(=\right.$ KCTC $12207^{\top}=$ IAM $\left.15115^{\top}\right)$ be classified as the type strains of two novel Pseudoxanthomonas species, for which the names Pseudoxanthomonas koreensis sp. nov. and Pseudoxanthomonas daejeonensis sp. nov., respectively, are proposed.
\end{abstract}

The order 'Xanthomonadales', the nomenclature of which was suggested in the most recent edition of Bergey's Manual of Systematic Bacteriology (Garrity \& Holt, 2001), is one of 14 orders within the class 'Gammaproteobacteria' and contains only one family, the 'Xanthomonadaceae'. The genus Pseudoxanthomonas, which belongs to the family 'Xanthomonadaceae', was first described by Finkmann et al. (2000). At the time of writing, the genus Pseudoxanthomonas consists of two species with validly published names, Pseudoxanthomonas broegbernensis (Finkmann et al., 2000) and Pseudoxanthomonas taiwanensis (Chen et al., 2002). Phylogenetically, the genus Pseudoxanthomonas is most closely related to the genera Xanthomonas,

Published online ahead of print on 22 October 2004 as DOI 10.1099/ ijs.0.63210-0.

The GenBank/EMBL/DDBJ accession numbers for the 16S rRNA gene sequences of strains $T 7-09^{\top}$ and TR6-08 ${ }^{\top}$ are AY550263 and AY550264, respectively.
Stenotrophomonas, Xylella and Luteimonas in the family 'Xanthomonadaceae'.

In this study, two strains were isolated from soil from a ginseng field in Daejeon, a city in South Korea, and were characterized by using polyphasic approaches. The polyphasic taxonomic analyses indicated that these bacteria represented novel species within the genus Pseudoxanthomonas.

\section{5 rRNA gene sequence studies}

$16 \mathrm{~S}$ rRNA gene sequences were analysed as described by Yoon et al. (1997, 1998). The 16S rRNA gene sequences of $\mathrm{T} 7-09^{\mathrm{T}}$ and TR6- $08^{\mathrm{T}}$ consisted of 1419 and $1462 \mathrm{nt}$, respectively. The $16 \mathrm{~S}$ rRNA gene sequences of related taxa were obtained from GenBank. The two isolates shared $99.5 \%$ sequence similarity. Strains $\mathrm{T} 7-09^{\mathrm{T}}$ and TR6- $08^{\mathrm{T}}$ were shown to belong to the Proteobacteria; the highest sequence similarities were found with respect to 
P. broegbernensis DSM $12573^{\mathrm{T}}(98 \cdot 1 \%)$, Pseudoxanthomonas mexicana AMX $26 \mathrm{~B}^{\mathrm{T}}(97 \cdot 4-97 \cdot 5 \%)$, Pseudoxanthomonas japonensis $12-3^{\mathrm{T}}(96 \cdot 5-96 \cdot 6 \%)$, P. taiwanensis ATCC BAA$404^{\mathrm{T}}(95 \cdot 7 \%)$ and Xanthomonas campestris ATCC $33913^{\mathrm{T}}$ $(96 \cdot 3-96 \cdot 5 \%)$. The sequence similarities from any species with validly published names in related genera were less than $96.5 \%$. Multiple alignments were performed with the CLUSTAL_X program (Thompson et al., 1997), gaps were edited using the BioEdit program (Hall, 1999) and evolutionary distances were calculated using the Kimura twoparameter model (Kimura, 1983). The phylogenetic tree was constructed by using a neighbour-joining method (Saitou \& Nei, 1987) in the MEGA 2.0 program (Kumar et al., 2001), with bootstrap values based on 100 replications (Felsenstein, 1985). Phylogenetically, the two isolates were located on the Pseudoxanthomonas lineage, and the degree of branching was supported by high bootstrap values (Fig. 1).

\section{DNA studies}

The DNA G + C contents of strains T7-09 ${ }^{\mathrm{T}}$ and TR6-08 ${ }^{\mathrm{T}}$ were analysed according to the methods of Mesbah et al. (1989) and Tamaoka \& Komagata (1984) and were determined to be $69 \cdot 5 \pm 0.5 \mathrm{~mol} \%$ and $68 \cdot 7 \pm 0.4 \mathrm{~mol} \%$, respectively. DNA-DNA hybridization experiments were carried out as described previously (Ezaki et al., 1989). Strain T7$09^{\mathrm{T}}$ hybridized with $P$. broegbernensis DSM $12573^{\mathrm{T}}$ and TR6- $08^{\mathrm{T}}$ at $2 \cdot 8$ and $3 \cdot 4 \%$, respectively, while strain TR6$08^{\mathrm{T}}$ hybridized with $P$. broegbernensis DSM $12573^{\mathrm{T}}$ and T7 $-09^{\mathrm{T}}$ at 28.9 and $7 \cdot 6 \%$, respectively. The results demonstrated that strain $\mathrm{T} 7-09^{\mathrm{T}}$ and strain TR6-08 ${ }^{\mathrm{T}}$ represent species that are separate from $P$. broegbernensis.

\section{Chemotaxonomic characteristics}

The results of chemotaxonomic analyses are given in the species description. The quinone systems of both isolates, which were analysed according to the procedures of Collins \& Jones (1981) and Shin et al. (1996), contained Q-8 as the predominant ubiquinone. The quinone system is in accordance with the characteristics of species of the genera Pseudoxanthomonas and Xanthomonas.

Cells used for analysis of cellular fatty acids were cultivated on trypticase soy agar (TSA) at $30{ }^{\circ} \mathrm{C}$ for $48 \mathrm{~h}$, then saponified, methylated and extracted according to the protocol of the Sherlock Microbial Identification System (MIDI). Fatty acids, analysed using a Hewlett Packard 6890 gas chromatograph, were identified by the Microbial Identification software package (Sasser, 1990). Both isolates had fatty acid profiles similar to those of $P$. broegbernensis DSM $12573^{\mathrm{T}}$ and $P$. taiwanensis ATCC BAA-404 ${ }^{\mathrm{T}}$, which contained $\mathrm{C}_{15 \text { :0 }}$ iso as the predominant acid (Table 1). Both isolates also had another major fatty acid, $\mathrm{C}_{17: 1}$ iso $\omega 9 c$, which differentiates them from other reference species of the genus Pseudoxanthomonas. Moderate amounts of $\mathrm{C}_{15: 0}$ anteiso, $\mathrm{C}_{16: 0}$ iso, $\mathrm{C}_{16: 1} \omega 9 c, \mathrm{C}_{17: 0}$ iso and unknown $12 \cdot 075$ were also detected.

\section{Phenotypic characteristics}

During the characterization of organisms isolated from soil from the ginseng field, strains $\mathrm{T} 7-09^{\mathrm{T}}$ and $\mathrm{TR} 6-08^{\mathrm{T}}$ were cultured on R2A agar (Difco) at $30^{\circ} \mathrm{C}$, on which they appeared as white $\left(\mathrm{T} 7-09^{\mathrm{T}}\right)$ or yellow $\left(\mathrm{TR} 6-08^{\mathrm{T}}\right)$ colonies. On this agar, both isolates were able to grow at $30-37^{\circ} \mathrm{C}$, but not at 4 or $60{ }^{\circ} \mathrm{C}$. Growth at $30^{\circ} \mathrm{C}$ was also observed on nutrient agar and TSA.

Gram reactions were tested by using the non-staining method described by Buck (1982). Cell morphology and motility were observed under a Nikon light microscope ( $\times 1000$ ), with cells grown for 3 days at $30{ }^{\circ} \mathrm{C}$ on R2A agar. The results of physiological characterization are given in the species description. Utilization of substrates as sole carbon sources and other physiological characteristics were determined with the API 32GN and API 20NE galleries, according to the instructions of the manufacturer (bioMérieux).

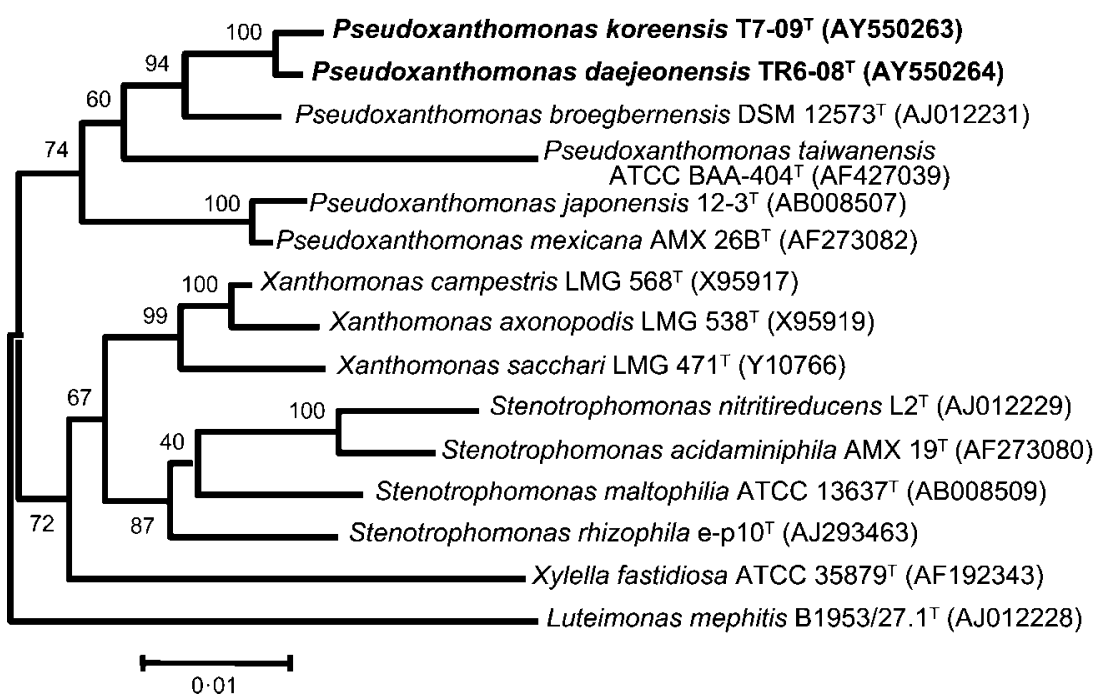

Fig. 1. Phylogenetic tree, based on $16 \mathrm{~S}$ rRNA gene sequences, showing the phylogenetic relationships of Pseudoxanthomonas species and related genera. The tree was constructed by using the neighbour-joining method, using 16S rRNA gene sequences. Bootstrap values, expressed as percentages of 100 replications, are shown at the branch points. Bar, 0.01 substitution per nucleotide position. 
Table 1. Cellular fatty acid profiles of strains $T 7-09^{\top}$ and $T R 6-08^{\top}$ and other species of the genus Pseudoxanthomonas

Strains: 1 , P. koreensis T7-09 $; 9^{\mathrm{T}}$ 2, P. daejeonensis TR6-08 ${ }^{\mathrm{T}} ; 3$, P. broegbernensis DSM $12573^{\mathrm{T}}$ (Chen et al., 2002); 4, P. taiwanensis ATCC BAA- $404^{\mathrm{T}}$ (Chen et al., 2002); 5, P. mexicana AMX $26 \mathrm{~B}^{\mathrm{T}}$ (Thierry et al., 2004); 6, P. japonensis $12-3^{\mathrm{T}}$ (Thierry et al., 2004). Strains $\mathrm{T} 7-09^{\mathrm{T}}$ and TR6- $08^{\mathrm{T}}$ were cultured on TSA at $30^{\circ} \mathrm{C}$ for $48 \mathrm{~h}$ and compared with other type strains under the same conditions. The values shown are percentages of total fatty acids. Unknown fatty acids (with equivalent chain-lengths) are shown.

\begin{tabular}{|c|c|c|c|c|c|c|}
\hline Fatty acid & 1 & 2 & 3 & 4 & 5 & 6 \\
\hline \multicolumn{7}{|l|}{ Saturated } \\
\hline $\mathrm{C}_{14: 0}$ & & & $12 \cdot 0$ & $6 \cdot 4$ & $0 \cdot 4$ & $0 \cdot 4$ \\
\hline $\mathrm{C}_{15: 0}$ & & & & $0 \cdot 9$ & & \\
\hline $\mathrm{C}_{16: 0}$ & & $1 \cdot 2$ & $1 \cdot 3$ & $4 \cdot 0$ & $0 \cdot 5$ & $0 \cdot 7$ \\
\hline $\mathrm{C}_{17: 0}$ & & & $1 \cdot 5$ & $2 \cdot 5$ & & \\
\hline $\mathrm{C}_{17: 0} \Delta$ & & & $1 \cdot 1$ & & & \\
\hline \multicolumn{7}{|l|}{ Unsaturated } \\
\hline $\mathrm{C}_{16: 1}$ cis7 $\left(\mathrm{C}_{16: 1} \omega 9 c\right)$ & $2 \cdot 3$ & $6 \cdot 7$ & & & & \\
\hline $\mathrm{C}_{16: 1}$ cis 9 & & & $1 \cdot 0$ & & & \\
\hline $\mathrm{C}_{18: 1}$ cis 11 & & & & & & $0 \cdot 5$ \\
\hline \multicolumn{7}{|l|}{ Methyl-branched } \\
\hline $\mathrm{C}_{11: 0}$ iso & & & $1 \cdot 4$ & & $5 \cdot 4$ & $4 \cdot 7$ \\
\hline $\mathrm{C}_{14: 0}$ iso & & $2 \cdot 2$ & & & $2 \cdot 1$ & $2 \cdot 4$ \\
\hline $\mathrm{C}_{15: 0}$ anteiso & $1 \cdot 0$ & $6 \cdot 9$ & $31 \cdot 8$ & $11 \cdot 3$ & $2 \cdot 6$ & $3 \cdot 9$ \\
\hline $\mathrm{C}_{15: 0}$ iso & $46 \cdot 2$ & $40 \cdot 5$ & $32 \cdot 4$ & $27 \cdot 3$ & $39 \cdot 7$ & $33 \cdot 0$ \\
\hline $\mathrm{C}_{15: 1}$ iso $\mathrm{F}$ & & & & & $1 \cdot 3$ & $1 \cdot 5$ \\
\hline$C_{15: 1}$ iso $G$ & $1 \cdot 5$ & & & & & \\
\hline $\mathrm{C}_{16: 0}$ iso & $6 \cdot 8$ & $8 \cdot 0$ & $6 \cdot 9$ & $35 \cdot 9$ & $9 \cdot 7$ & $12 \cdot 7$ \\
\hline $\mathrm{C}_{16: 1}$ iso $\mathrm{H}$ & & & & & $3 \cdot 9$ & $4 \cdot 1$ \\
\hline $\mathrm{C}_{17: 0}$ anteiso & & & & & $0 \cdot 4$ & $0 \cdot 6$ \\
\hline $\mathrm{C}_{17: 0}$ iso & $7 \cdot 8$ & $3 \cdot 6$ & & $3 \cdot 3$ & $4 \cdot 9$ & $3 \cdot 5$ \\
\hline $\mathrm{C}_{17: 1}$ anteiso cis7 & & & & & & $0 \cdot 5$ \\
\hline $\mathrm{C}_{17: 1}$ iso cis7 $\left(\mathrm{C}_{17: 1}\right.$ iso $\left.\omega 9 c\right)$ & $24 \cdot 4$ & $20 \cdot 3$ & & & $18 \cdot 5$ & $19 \cdot 9$ \\
\hline $\mathrm{C}_{17: 1}$ iso cis 9 & & & $5 \cdot 5$ & $4 \cdot 3$ & & $0 \cdot 5$ \\
\hline $\mathrm{C}_{18: 1}$ iso $\mathrm{H}$ & & & & & $0 \cdot 7$ & $0 \cdot 7$ \\
\hline \multicolumn{7}{|l|}{ Hydroxy } \\
\hline $\mathrm{C}_{11: 0}$ iso $2-\mathrm{OH}$ & & & $0 \cdot 9$ & & & \\
\hline $\mathrm{C}_{11: 0}$ iso $3-\mathrm{OH}$ & & & $1 \cdot 0$ & & $6 \cdot 5$ & $5 \cdot 2$ \\
\hline $\mathrm{C}_{16: 0} 2-\mathrm{OH}$ & & & $0 \cdot 9$ & $1 \cdot 4$ & & \\
\hline \multicolumn{7}{|l|}{ Summed feature } \\
\hline $\mathrm{C}_{16: 1}$ cis $9 / \mathrm{C}_{15: 0}$ iso $2-\mathrm{OH}$ & & & & & $3 \cdot 2$ & $4 \cdot 5$ \\
\hline $\mathrm{C}_{17: 1}$ iso I/anteiso B & & & & & $0 \cdot 3$ & $0 \cdot 5$ \\
\hline \multicolumn{7}{|l|}{ Unknown } \\
\hline Unknown $10 \cdot 570$ & & $4 \cdot 3$ & & & & \\
\hline Unknown $10 \cdot 575$ & $2 \cdot 7$ & & & & & \\
\hline Unknown $12 \cdot 075$ & $6 \cdot 5$ & $4 \cdot 8$ & & & & \\
\hline Unknown $13 \cdot 566$ & & $1 \cdot 6$ & & & & \\
\hline Unknown $13 \cdot 606$ & $0 \cdot 8$ & & & & & \\
\hline
\end{tabular}

Reduction of nitrate and nitrite was confirmed by inoculating cells, in each case, into three serum bottles $(25 \mathrm{ml})$ containing $13 \mathrm{ml} \mathrm{R} 2 \mathrm{~A}$ medium; nitrate or nitrite was added (as $\mathrm{KNO}_{3}$ or $\mathrm{NaNO}_{2}$ ) at concentrations up to $10 \mathrm{mM}$. The reduction of nitrate and nitrite was monitored by using an ion chromatograph (model 790 personal IC; Metrohm) equipped with a conductivity detector and an anionexchange column (Metrosep Anion Supp 4; JL Science); gas production was observed by using small tubes turned upside down in the serum bottles and by using GC.

\section{Taxonomic considerations}

$16 \mathrm{~S}$ rRNA gene sequence comparisons and chemotaxonomic characteristics of the isolates suggest the assignment of strains $\mathrm{T} 7-09^{\mathrm{T}}$ and $\mathrm{TR} 6-08^{\mathrm{T}}$ to the genus 
Pseudoxanthomonas. The DNA-DNA hybridization results, together with the unique physiological profiles of the isolates, demonstrated that strain $\mathrm{T} 7-09^{\mathrm{T}}$ and strain TR6$08^{\mathrm{T}}$ each represent a separate species within the genus Pseudoxanthomonas. These two strains showed very low levels of DNA-DNA hybridization with P. broegbernensis, and were also distant from $P$. taiwanensis, $P$. mexicana and
P. japonensis in the phylogenetic tree. On the basis of these data, T7-09 $\left(=\right.$ KCTC $12208^{\mathrm{T}}=$ IAM $\left.15116^{\mathrm{T}}\right)$ and TR6-08 ${ }^{\mathrm{T}}$ $\left(=\right.$ KCTC $12207^{\mathrm{T}}=$ IAM $15115^{\mathrm{T}}$ ) should be classified as the type strains of two novel Pseudoxanthomonas species, for which the names Pseudoxanthomonas koreensis sp. nov. and Pseudoxanthomonas daejeonensis sp. nov., respectively, are proposed.

Table 2. Differential phenotypic characteristics for strains $T 7-09^{\top}$ and $T R 6-08^{\top}$ and related species

Strains: 1, P. koreensis T7-09 ${ }^{\mathrm{T}} ; 2$, P. daejeonensis TR6- $08^{\mathrm{T}} ; 3$, P. broegbernensis DSM $12573^{\mathrm{T}}$ (Chen et al., 2002); 4, P. taiwanensis ATCC BAA- $404^{\mathrm{T}}$ (Chen et al., 2002); 5, P. mexicana AMX 26B ${ }^{\mathrm{T}}$ (Thierry et al., 2004); 6, P. japonensis $12-3^{\mathrm{T}}$ (Thierry et al., 2004). Symbols: +, positive; -, negative; +/-, weakly positive; V, variable; ND, no data. Strains $\mathrm{T} 7-09^{\mathrm{T}}$ and TR6- $08^{\mathrm{T}}$ are negative for assimilation of 3-hydroxybenzoate, 4-hydroxybenzoate, 2-ketogluconate, 5-ketogluconate, adipate, caprate, L-fucose, gluconate, itaconate, DL-lactate, malonate, phenyl acetate, propionate, suberate, valerate, D-ribose, mannitol, L-histidine, glycogen and salicin.

\begin{tabular}{|c|c|c|c|c|c|c|}
\hline Characteristic & 1 & 2 & 3 & 4 & 5 & 6 \\
\hline Motility & - & + & + & - & + & + \\
\hline Nitrite reduction to $\mathrm{N}_{2} \mathrm{O}$ & - & - & + & + & ND & $\mathrm{ND}$ \\
\hline Nitrate reduction to $\mathrm{N}_{2}$ & - & - & - & - & ND & $\mathrm{ND}$ \\
\hline Catalase & + & + & + & + & $+1-$ & - \\
\hline Optimum growth temperature $\left({ }^{\circ} \mathrm{C}\right)$ & 30 & 30 & 30 & 50 & $30-37$ & $30-37$ \\
\hline \multicolumn{7}{|l|}{ Growth at: } \\
\hline $10^{\circ} \mathrm{C}$ & $+1-$ & $+1-$ & + & - & + & + \\
\hline $37^{\circ} \mathrm{C}$ & + & + & - & + & + & + \\
\hline $42^{\circ} \mathrm{C}$ & - & - & - & + & - & - \\
\hline \multicolumn{7}{|l|}{ Enzyme activity } \\
\hline Arginine dihydrolase & + & - & - & ND & ND & ND \\
\hline Urease & + & - & - & $\mathrm{ND}$ & ND & ND \\
\hline$\beta$-Glucosidase (aesculin hydrolysis) & - & + & - & + & ND & ND \\
\hline$\beta$-Galactosidase & - & + & + & + & - & + \\
\hline Protease (gelatin hydrolysis) & - & - & - & - & + & + \\
\hline Protease (casein hydrolysis) & + & + & - & - & + & + \\
\hline \multicolumn{7}{|l|}{ Assimilation of: } \\
\hline 3-Hydroxybutyrate & - & + & - & $\mathrm{ND}$ & + & + \\
\hline Citrate & - & - & + & $\mathrm{ND}$ & - & - \\
\hline DL-Lactate & - & - & - & $\mathrm{ND}$ & - & + \\
\hline Malate & - & - & - & - & - & + \\
\hline Propionate & - & - & - & $\mathrm{ND}$ & + & + \\
\hline L-Arabinose & - & + & + & - & - & - \\
\hline D-Glucose & - & + & + & + & ND & $\mathrm{ND}$ \\
\hline Maltose & - & + & + & - & + & + \\
\hline D-Mannose & - & - & + & - & + & - \\
\hline D-Melibiose & - & + & + & - & - & - \\
\hline D-Sucrose & - & - & + & - & - & - \\
\hline myo-Inositol & - & - & - & - & ND & ND \\
\hline Mannitol & - & - & - & $\mathrm{ND}$ & ND & $\mathrm{ND}$ \\
\hline D-Sorbitol & - & - & - & - & ND & ND \\
\hline$N$-Acetylglucosamine & - & + & + & $\mathrm{ND}$ & ND & $\mathrm{ND}$ \\
\hline L-Alanine & - & + & - & - & ND & ND \\
\hline L-Histidine & - & - & - & $\mathrm{ND}$ & + & + \\
\hline L-Proline & - & - & + & + & + & - \\
\hline L-Serine & - & - & - & - & + & $\mathrm{V}$ \\
\hline
\end{tabular}




\section{Description of Pseudoxanthomonas koreensis sp. nov.}

Pseudoxanthomonas koreensis (ko.re.en'sis. N.L. fem. adj. koreensis pertaining to Korea, the location of the soil sample from which the type strain was isolated).

Cells are Gram-negative, oxidase-positive with an oxidative metabolism, catalase-positive, non-spore-forming, nonmotile rods. Good growth occurs aerobically on R2A agar, nutrient agar and TSA at $30^{\circ} \mathrm{C}$; white, semi-translucent, non-shiny colonies with entire edges form within 3 days, having diameters of approximately $1 \cdot 5-3 \mathrm{~mm}$. The quinone system consists of Q-8. The fatty acid profile is largely composed of $\mathrm{C}_{15: 0}$ iso and $\mathrm{C}_{17: 1}$ iso $\omega 9 \mathrm{c}$. The $\mathrm{G}+\mathrm{C}$ content of the genomic DNA is high $(69.5 \pm 0.5 \mathrm{~mol} \%)$. Differential phenotypic characteristics are summarized in Table 2.

The type strain, T7-09 ${ }^{\mathrm{T}}\left(=\mathrm{KCTC} 12208^{\mathrm{T}}=\mathrm{IAM} 15116^{\mathrm{T}}\right.$ ), was isolated from soil from a ginseng field in Daejeon, South Korea.

\section{Description of Pseudoxanthomonas daejeonensis sp. nov.}

Pseudoxanthomonas daejeonensis (dae.je.on.en'sis. N.L. fem. adj. daejeonensis pertaining to Daejeon in Korea, the location of the soil sample from which the type strain was isolated).

Cells are Gram-negative, oxidase-positive with an oxidative metabolism, catalase-positive, non-spore-forming, motile rods. Good growth occurs aerobically on R2A agar, nutrient agar and TSA at $30^{\circ} \mathrm{C}$; yellow, semi-translucent and nonshiny colonies with entire edges form within 3 days, having diameters of approximately $1 \cdot 5-3 \mathrm{~mm}$. The quinone system consists of Q-8. The fatty acid profile is largely composed of $\mathrm{C}_{15: 0}$ iso and $\mathrm{C}_{17: 1}$ iso $\omega 9 \mathrm{c}$. The $\mathrm{G}+\mathrm{C}$ content of the genomic DNA is high $(68 \cdot 7 \pm 0.4 \mathrm{~mol} \%)$. Differential phenotypic characteristics are summarized in Table 2.

The type strain, TR6- $08^{\mathrm{T}}\left(=\mathrm{KCTC} 12207^{\mathrm{T}}=\mathrm{IAM} 15115^{\mathrm{T}}\right)$, was isolated from soil from a ginseng field in Daejeon, South Korea.

\section{References}

Buck, J. D. (1982). Nonstaining (KOH) method for determination of gram reactions of marine bacteria. Appl Environ Microbiol 44, 992-993.

Chen, M.-Y., Tsay, S.-S., Chen, K.-Y., Shi, Y.-C., Lin, Y.-T. \& Lin, G.-H. (2002). Pseudoxanthomonas taiwanensis sp. nov., a novel thermophilic, $\mathrm{N}_{2} \mathrm{O}$-producing species isolated from hot springs. Int J Syst Evol Microbiol 52, 2155-2161.

Collins, M. D. \& Jones, D. (1981). Distribution of isoprenoid quinone structural types in bacteria and their taxonomic implications. Microbiol Rev 45, 316-354.
Ezaki, T., Hashimoto, Y. \& Yabuuchi, E. (1989). Fluorometric deoxyribonucleic acid-deoxyribonucleic acid hybridization in microdilution wells as an alternative to membrane filter hybridization in which radioisotopes are used to determine genetic relatedness among bacterial strains. Int J Syst Bacteriol 39, 224-229.

Felsenstein, J. (1985). Confidence limits on phylogenies: an approach using the bootstrap. Evolution 39, 783-791.

Finkmann, W., Altendorf, K., Stackebrandt, E. \& Lipski, A. (2000). Characterization of $\mathrm{N}_{2} \mathrm{O}$-producing Xanthomonas-like isolates from biofilters as Stenotrophomonas nitritireducens sp. nov., Luteimonas mephitis gen. nov., sp. nov. and Pseudoxanthomonas broegbernensis gen. nov., sp. nov. Int J Syst Evol Microbiol 50, 273-282.

Garrity, G. M. \& Holt, J. G. (2001). The road map to the Manual. In Bergey's Manual of Systematic Bacteriology, 2nd edn, vol. 1, pp. 119166. Edited by G. M. Garrity, D. R. Boone \& R. W. Castenholz. New York: Springer.

Hall, T. A. (1999). BioEdit: a user-friendly biological sequence alignment editor and analysis program for Windows 95/98/NT. Nucleic Acids Symp Ser 41, 95-98.

Kimura, M. (1983). The Neutral Theory of Molecular Evolution. Cambridge: Cambridge University Press.

Kumar, S., Tamura, K., Jakobsen, I. B. \& Nei, M. (2001). MEGA2: molecular evolutionary genetics analysis software. Bioinformatics $\mathbf{1 7}$, 1244-1245.

Mesbah, M., Premachandran, U. \& Whitman, W. B. (1989). Precise measurement of the $\mathrm{G}+\mathrm{C}$ content of deoxyribonucleic acid by high-performance liquid chromatography. Int J Syst Bacteriol 39, 159-167.

Saitou, N. \& Nei, M. (1987). The neighbor-joining method: a new method for reconstructing phylogenetic trees. Mol Biol Evol 4, 406-425.

Sasser, M. (1990). Identification of Bacteria by Gas Chromatography of Cellular Fatty Acids. MIDI Technical Note 101. Newark, DE: MIDI.

Shin, Y. K., Lee, J.-S., Chun, C. O., Kim, H.-J. \& Park, Y.-H. (1996). Isoprenoid quinone profiles of the Leclercia adecarboxylata KCTC $1036^{\mathrm{T}}$. J Microbiol Biotechnol 6, 68-69.

Tamaoka, J. \& Komagata, K. (1984). Determination of DNA base composition by reversed-phase high-performance liquid chromatography. FEMS Microbiol Lett 25, 125-128.

Thierry, S., Macarie, H., lizuka, T. \& 9 other authors (2004). Pseudoxanthomonas mexicana sp. nov. and Pseudoxanthomonas japonensis sp. nov., isolated from diverse environments, and emended descriptions of the genus Pseudoxanthomonas Finkmann et al. 2000 and of its type species. Int J Syst Evol Microbiol 54, 2245-2255.

Thompson, J. D., Gibson, T. J., Plewniak, F., Jeanmougin, F. \& Higgins, D. G. (1997). The CLUSTAL_X Windows interface: flexible strategies for multiple sequence alignment aided by quality analysis tools. Nucleic Acids Res 25, 4876-4882.

Yoon, J.-H., Lee, S.-T., Kim, S.-B., Kim, W. Y., Goodfellow, M. \& Park, Y.-H. (1997). Restriction fragment length polymorphism analysis of PCR-amplified 16S ribosomal DNA for rapid identification of Saccharomonospora strains. Int J Syst Bacteriol 47, 111-114.

Yoon, J.-H., Lee, S.-T. \& Park, Y.-H. (1998). Inter- and intraspecific phylogenetic analysis of the genus Nocardioides and related taxa based on $16 \mathrm{~S}$ rDNA sequences. Int J Syst Bacteriol 48, $187-194$. 